\title{
Bill Business Risk and Prevention of Small and Medium Commercial Bank
}

\author{
Yanling Hu \\ Civil, Commercial and Economic Law School, China University of Political Science and Law \\ Beijing, 100088, China \\ E-mail: lxfhyl@163.com \\ Received 22 September 2014 \\ Accepted 19 November 2014
}

\begin{abstract}
With the increasingly fierce competition in China's banking industry, the traditional deposit and loan business has been difficult to meet the needs of the development of banking business itself. Bill business as a new intermediary business has been a new point of profit growth for small and medium commercial banks (SMCB). However, with the development of bill business, the relevant problems have been exposed. This paper proposes corresponding countermeasures on these problems and focuses on the risks should be noticed in doing bill business and the preventive measures to SMBCs.
\end{abstract}

Keywords: Small and medium commercial bank; Bill business; Risk; Prevention

\section{Introduction}

In the recent years, the bill business of SMCB develops rapidly, which has been playing a positive role in nurturing relation between bank and enterprise, enhancing service function, optimizing asset structure, decentralizing business risk, and to a certain extent, broadens financing channels, supports the development of SMCB (Chun, 2014).

However, oppositely, there is idea bias in some SMCBs, they are obsessed with market share but weak in risk awareness. There is no strict internal control and management on bill business and there are many irregularities and risk issues. If these problems can not be solved timely, they will affect the healthy development of bill business market and the sound operation of SMBC.

\section{The Main Risks in Bill Business}

\subsection{Credit risk}

In the absence or deficiency of margin, issuing or discounting acceptance bills leads to much bank advance and thereby results in credit exposure risk. Mainly as follows:

First, do not charge the margin as specified proportion or the amount is low.

Second, shortfall guarantee to the shortfall part of margin or warranty is invalid, for example: the amount of guarantee contract is less than the shortfall part of margin, the guarantee company is lack of guarantee capacity, the pledge is not in comply with relevant provisions, the procedures of pledge is not timely or normally handled, guaranteed by affiliates or mutual guarantee, the guarantee contract is without agreement result form the board, etc (Xue and Xiao, 2014).

Third, use their own loan as margin to issue acceptance bill, or transferring loan to fixed deposit as 
pledge to apply for acceptance bill. These practices of the bank actually transfer the acceptance risk to credit risk, but it finally do not ascertain the payment source and also inflates the size of deposit and loan. Through expanding the size of deposit, loan and bill business in such non-normal ways, forms a vicious circle like this "enterprise uses loan fund as margin $\rightarrow$ bank issues acceptance bill $\rightarrow$ enterprise discounts the acceptance $\rightarrow$ enterprise uses the discounted money as margin $\rightarrow$ bank issues acceptance again $\rightarrow$ enterprise discount acceptance again...." In the iterative process, credit expands, loan multiplies illusorily, forms credit bubble.

Fig.1 The date of Commicial Bills and Bills Discounted in 2013 and 2012

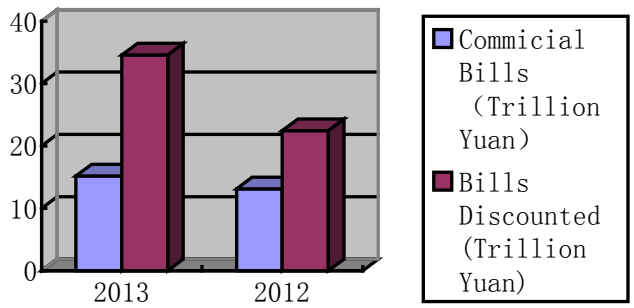

\subsection{Financing risk}

Financing Risk is caused by commercial bank issuing or discounting acceptance bill without real transaction background or unknown real transaction background. It's characters are: no contract or using false or invalid contract; issuing or discounting beyond contract amount or date; no copy of value-added tax invoice, reusing the same invoice or forged invoice (Duan, 2013).

Some banks, under the guise of enterprises, open accounts illegally. They use these accounts to issue acceptance bills and then make them discounted in other banks, bring money back to their own bank and make their saving in increase. They call it "Financing Deposits". Issuing or discounting bills without real transaction, the bank is in violation of relevant provisions of Payment and Settlement Method and Commercial bank bill acceptance and discount and rediscount Interim Measures.

Therefore, doing like this the banks are undertaking financing risk and at the same time, potential legal risk.

\subsection{Morality risk}

First, affiliated enterprises, affiliated transaction parties collude with each other, to cash bank funds. The main way is: drawer and payee are affiliated enterprises or affiliated transaction parties, the drawer use proportional margin to apply for acceptance, then the insufficient part is guaranteed by the payee, finally the money flows from the payee's account to the drawer's account, realizing the reverse flow of capital.

Second, some unscrupulous people use forged or altered notes, "cloning" bills or notes "switching" to defraud the bank funds consciously and make the bank face financial loss.

Third, the bank's internal stuff do not strictly control the "three checks": the check of legitimacy and compliance of items on bills, the check of endorsement verification, the check of authenticity of bills, or someone illegally and irregularly embezzles bank bills, thus leave bank suffers financial losses.

\subsection{Interest rate risk and liquidity risk}

The four state-owned commercial banks seldom provide credit to small and medium enterprises, their loan and the loan of small project is usually carried out this way: the small and medium banks discount acceptance bills, and then they rediscount from the four state-owned commercial banks.

SMCBs earn the spread in bill market. Once market funds are tight, rediscount interest rates rise, small banks will face interest rate risk, and will lead to severe liquidity risks (Jue, 2012).

\subsection{Handle risk}

First, discount in advance and check afterwards--reverse handle. In order to win business and enhance competitiveness, some banks ask enterprises to issue letter of commitment for discounting. First, however, the checking date is a few days or half a month late than the expenditure presentation date (Bo, 2012). The way of discounting acceptance without assured checking carries certain risks and makes it difficult to ensure the safety of bank capital.

Second, the bill endorsement obtained by discount and pledge is illegal and incomplete. Mainly like this: open endorsement when discounted, discontinuous multiple endorsement, etc. This not only goes against Bills of Exchange Act, but also makes the bank 
impossible to claim bill right when bill dispute or bill loss happened, what's more this is easy to trigger morality risk.

\subsection{Internal management risk}

The foundation work of some SMCB is weak, there is safety risk in bill kept and used, what's more, ineffective internal controls, resulting in bills cases occur frequently, risk and loss continue to produce.

At present most SMCBs, in vary degrees, have the issue of archives incomplete and irregularities, such as, acceptance agreement, transaction contract are incomplete, the basic documents of acceptance applier is incomplete and convention records are not detailed (Dan, 2009). Some banks exist account and the actual inconsistent, account and account inconsistent, don't implement "three separate charge" of seal, mortgage, and voucher.

There is no supervision over seal take-over, make errors in accounting margin, use administrative seal instead of settlement seal in the consignment collection of acceptance bill.

\section{Reasons of Bills Business Risk}

\subsection{Backward invoice anti-counterfeit means}

In-conformity information between bank, enterprise and backward involves anti-counterfeit means. Some enterprise is weak in legal awareness, they forge contract or invoice to defraud bank funds. What's worse, the sharing mechanism is imperfect, such as banks haven't networked with tax department, can not query the authenticity of the invoice; the credit registration information system also lacks information about acceptance bill discount.

In addition, the invoice and contract offered by companies are not matched, a few enterprises can not offer value-added invoice, which brings difficulties for banks to check the real transactions background. Because of lacking unified bill issue, query, and certificate system and institution, the electronization level of bills is low, leaving an opportunity to "fake bill” and" cloning bill”.

\subsection{Imperfect legal system}

The provisions of the current Bills of Exchange Act, Payment and Settlement Method and Commercial bank bill acceptance and discount and rediscount Interim
Measures are too general, have not made judicial interpretations about discount, transfer discount, rediscount business that involve bill business, and lack of legal basis in regulation.

First, there is no monitoring index to acceptance business. In 2002, PBOC canceled the requirement that the total amount of acceptance bills can be lager than the $5 \%$ of the ending balance last year, and there is no other guidance issued. For small financial institutions with small assets scale and low risk control ability, lacking of external constraints, is likely to cause the blind development.

Second, there are no unified regulations to government of acceptance margin, way of charging and amount of margin and no define and punishment standard to transferring loan to margin.

Third, there are no regulatory measures to enterprise's practice of opening accounts in different names and reusing value-added invoice to discount in different banks.

\subsection{Management malposition and enlarge business blindly}

SMCBs are restricted from operating zones, most of them have the problem of financial strain and small business scale. Bill business has the scale expansion function, can bring banks extra business.

Therefore SMCBs use bill business as the main way to enlarge business scale. Thorough offering loan or discounting for enterprise, banks make the money as margin or fixed deposit and then issue bills to enterprises, handling like this in circle, can realize the both growth of loan and deposit.

Second, bill business can dilute non-performing loan (NPL): through increasing bill business to enlarge loan scale, which makes the denominator bigger, the NPL rate smaller. Meanwhile, bill business can adjust profit, add operation revenue: through buy and sell bills to gain interests in advance, to adjust profit condition; when loan is used as margin, banks earn the loan interest, but pay deposit interest to enterprise, there for the interest margin becomes the revenue of the bank.

\subsection{Incomplete internal structure and weak risk consciousness}

SMCBs have generally established internal control system, but the operation process and responsibility 
system is not unified and strict enough to cover all the risk points, to effectively prevent risk. Some banks don't include all bill financing to the credit of a single customer, which is not good for controlling and preventing single customer's credit risk; some banks haven't implemented "three checks", can not clearly grasp the credit condition of enterprise; in a few banks, the training and periodic rotation of stuff in important position have not been formed to a system, which is bad for prevent operation risk and morality risk; there are also banks whose auditor is short-staffed, bring about the weak supervision over bill business.

\subsection{Discriminated by weak position}

SMCBs especially municipal commercial banks don't have a nationwide network, big banks agent their bill inquiry. Some agent banks discriminate small banks, deliberately delay the inquiry response. Since the slow response, the longest about one month, forces the authorized bank to discount in advance for enterprises in urgent need, or to simply discount at sight for big customers, forming handle risk in bill business.

\section{Bill Business Risk Prevention and Management}

\subsection{Strengthen internal control and improve the risk prevention mechanism}

SMCBs should adhere to the "internal control priority" principle, focus on risk management, strengthen the building of internal control mechanism, set up normative ticketing, registration, inquiry procedures and systems with strong operability, intensify the review and check of the authenticity of bills, and ensure the authenticity of bill transactions and the security of finance.

Meanwhile, each risk point in bill business procedure should be carefully predicted and analyzed. Each risk point should be set up with "firewall", and risk management procedure should be evaluated regularly.

SMCBs should also enhance staff training to raise the awareness of business risks, improve the staff's defensive skills and build up noble work ethics and strictly perform operation, check and supervision system (Shan and Qian, 2012).

\subsection{Correct business ideas and enhance the consciousness of risk prevention}

SMCBs should stop being obsessed with scale and speed, correctly handle the relationship between bill business development and risk prevention and avoid pursuing bill gains at the cost of assuming tremendous advances risks.

Comprehensive, coordinated and sustainable development view and scientific evaluation mechanism should be set up. The development goal and scheme of bill business should be established according to its own characteristics and actual situation. It should be avoided to be obsessed with scale and speed. Business development should be based on controllable risk.

\subsection{Strengthen compliance regulation and promote the healthy development of bill business}

Regulatory authorities should be fully aware of the potential risks in bill business, strengthen the efforts to on-site inspection, mainly examine bill acceptance and the authenticity of discount business's background, discounting cash flow, loans as deposit, inner control regime and risks in bill business etc (Ba and Bei, 2005).

Special attention should be paid to the regulation of the effectiveness of internal control, operant behavior and each risk point. Regulatory authorities should further strengthen the penalties for violations in bills business, strengthen supervision inspection, timely correct and handle illegal behaviors to maximize risk prevention and control.

\subsection{Perfect loan registration information system and solve the problem of asymmetric information}

PBC and regulatory authority should establish bank acceptance's issuing and discounting business database, achieve national network query function, improve working efficiency, connect with tax department, timely recognize the authenticity of VAT ticket copies or originals provided by enterprises, enhance the examination of trade background and prevent and mitigate risks.

\subsection{Revise the system and regulate the bill market}

Some items in the current Commercial Instrument law, Payment and settlement method, Commercial bank bill acceptance and discount and rediscount Interim 
Measures are not suitable for the development status of bills.

Admittance and retreating system for enterprises in bill business, the management of bill financing, bill transaction, bill credit evaluation, the price agreement of bill transaction, capital settlement and business risk reserve system etc. should be standardized as soon as possible.

From a regulatory point of view, specific regulations regarding commercial bank bill business risk control should be made.

First, bill financing should be wholly included in the range of credit authorization and customer credit to facilitate external regulation and internal control.

Second, directive monitoring index about total acceptance and acceptance proportion of single or ten household at most, and control regime regarding issuing to offset companies should be formulated to eliminate bubbles in bill market.

Third, security deposit raking management should be implemented or the zero norm of security should be regulated. The bill risk exposure should be linked with capital scale to reduce the acceptance risks of banks.

\section{Conclusions}

As a new intermediary business, bill business has been a new point of profit growth for small and medium commercial banks (SMCB).

However, with the development of bill business, the risks have been exposed. In order to prevent the bill business risk, SMCBs should take the following measure.

First, SMCBs should stop being obsessed with scale and speed, correctly handle the relationship between bill business development and risk prevention and avoid pursuing bill gains at the cost of assuming tremendous advances risks.

Second, clearly defined standards and punishment regulation regarding margin loads and affiliates obtaining bank credit should be formulated.

Third, require all the financial institutions that the original value-added invoice should be stamped, noting discount amount, discount institution name, to prevent rediscount by the same invoice from the very beginning.

\section{References}

S. S. Ba and J. Bei, Bills market research on development, Accounting Monthly (3) (2005) 15-16.
M. X. Bo, Risks and measures currently exist in bill business, Accountants (18) (2012) 25-26.

L. W. Chun, Analysis of commercial bank's bill business risks and preventive measures, Market Weekly (2) (2014) 80-82.

Z. Dan, Key point of China's commercial banks in the field of bill business risk prevention, Financial economics (18) (2009) 110-111.

Y. Duan, Joint-stock commercial bank bill business risk, financial era (24) (2013) 76.

Z. Jue, The business risk of commercial bank bills, Rethinking times of financial (35) (2012) 109.

C. Shan and X. Z. Qian, Characteristics and the Influence of Bank Bill Business, China Financial (5) (2012) 82-83.

C. Xue and L. Y. Xiao, Internal control problems of commercial banks' bill Business, modern economic information (16) (2014) 297-299. 